\title{
HPV-driven oropharyngeal cancer: current knowledge of molecular biology and mechanisms of carcinogenesis
}

\author{
Cassie Pan ${ }^{1}$, Natalia Issaeva ${ }^{2}$ and Wendell G. Yarbrough ${ }^{2^{*}}$ (B)
}

\begin{abstract}
Understanding of oropharyngeal squamous cell carcinoma has significantly progressed over the last decades, and the concept that this disease can be subdivided into two distinct entities based on human papilloma virus (HPV) status has gained acceptance. To combat the constantly growing epidemic of HPV+ oropharyngeal cancer, further investigation and characterization the unique features of the disease, along with the development and implementation of new, targeted therapies, is crucial. In this review, we summarize the etiology, pathogenesis, diagnosis, treatment, and molecular characteristics of HPV-associated oropharyngeal squamous cell carcinoma.
\end{abstract}

Keywords: Oropharyngeal cancer, HPV, Etiology, Treatment

\section{Background}

Head and neck squamous cell carcinomas comprise a diverse group of tumors, which are classified into anatomical subsites including oral cavity, oropharynx, hypopharynx, larynx, and nasopharynx. Cancers of different subsites are known to have unique epidemiology, anatomy, clinical behavior, and association with human papilloma virus (HPV) infection $[1,2]$. In this review, we will focus on HPV-driven oropharyngeal squamous cell carcinoma (OPSCC), which has become a matter of growing clinical urgency as its incidence has dramatically increased in recent years. Unique epidemiological, molecular, biological and clinical differences have led to the increasing recognition of HPV-positive OPSCCs as distinct from HPV-negative OPSCCs. This review article will summarize clinical and molecular characteristics of HPV-driven OPSCCs, focusing on factors that distinguish HPV-positive and HPV-negative OPSCCs and examining differences between OPSCC and uterine cervical cancer with attention to an alternative mechanism of HPV carcinogenesis.

\footnotetext{
* Correspondence: dell@med.unc.edu; natalia.isaeva@med.uc.edu

${ }^{2}$ Department of Otolaryngology/Head and Neck Surgery; Lineberger Cancer Center, University of North Carolina at Chapel Hill, 170 Manning Drive, Campus Box 7070, Chapel Hill, NC 27599, USA

Full list of author information is available at the end of the article
}

\section{Epidemiology}

In the late 20th and early twenty-first century, the campaign to reduce smoking decreased rates of tobacco-related cancers, including oral cavity and laryngeal cancers. During this same period, rates of oropharyngeal cancers increased [3-6]. With the growing number of OPSCCs, the etiologic role of HPV infection also burgeoned, and the percentage of OPSCCs associated with HPV increased from $20 \%$ in the 1980s to over 70\% by 2005 [7-9]. CDC statistics from 2012 revealed that the incidence of HPV-associated OPSCCs exceeded that of HPV-associated uterine cervical cancers, making OPSCC the most frequently diagnosed cancer caused by HPV [10]. As opposed to HPV-negative cancers of the head and neck, HPV(+) OPSCCs occur in younger patients with minimal or no tobacco exposure [11-16]. $\mathrm{HPV}(+)$ OPSCC has a male predominance with men suffering a three to five times higher incidence than women worldwide $[16,17]$.

Over $90 \%$ of $\mathrm{HPV}(+)$ OPSCC is caused by the high-risk HPV genotype 16, with almost all oral HPV infections thought to be sexually acquired [14, 18, 19]. The prevalence of oral HPV16 infection in ages 14-69 in the US is $\sim 1 \%$ ( $7 \%$ for all genotypes), with higher rates in men than in women [19]. The risk for oral HPV infection increases with the number of oral sexual partners, with the higher rates in men being possibly due to men performing oral sex on women and female genitalia 
carrying a higher HPV burden than male genitalia [17, 20]. Alternatively, since women have a higher seroconversion rate after genital HPV exposure, they may be relatively protected from oral infection [21].

Intense interest regarding the benefits of primary prevention of HPV infection has followed the introduction of HPV vaccines. The Gardasil four-valent vaccine covers HPV types 6, 11, 16, and 18 and received FDA approval for use in females in 2006 and in males in 2011. Since January 2017, the nine-valent Gardasil vaccine with expanded coverage, adding HPV types 31, 33, 45,52 , and 58 , has been the only HPV vaccine available in the US. The CDC currently recommends routine vaccination for both girls and boys at age 11-12, with vaccination recommended for females through age 26 and for males through age 21 [22].

A US-based study that examined the effects of HPV vaccination on the burden of oral HPV16 infections found that between 2011 and 2014, vaccination potentially prevented almost one hundred thousand infections [23]. However, due to low vaccine uptake in males, less than half of this effect was seen in men, representing a gap in targeting the most at-risk population [23]. Due to the tepid HPV vaccine uptake and the long latency of developing OPSCC following exposure, it is estimated that the epidemic of $\mathrm{HPV}(+)$ OPSCC will continue until 2060 [17].

\section{Diagnosis}

The 2018 version of The National Comprehensive Cancer Network Clinical Practice Guidelines in Oncology (USA) directs that OPSCCs be tested for HPV by p16 immunohistochemistry (IHC) [24]. p16 (p16 $\left.{ }^{\mathrm{INK} 4 \mathrm{a}}\right)$ IHC has been widely adopted because it is cost effective, reliable, examines paraffin-embedded tissue, and has high sensitivity $(94 \%)[25,26]$. IHC for p16 is particularly good for comparison of $\mathrm{HPV}(+)$ and $\mathrm{HPV}(-)$ HNSCC, because the protein is overexpressed in $\mathrm{HPV}(+)$ HNSCC and frequently lost in HNSCC not associated with HPV [27]. However, in various studies authors have reported that $8-33 \%$ of p16-positive OPSCCs lack HPV DNA, likely reflecting a combination of insensitive HPV detection techniques and that p16 overexpression occurs independently of HPV gene expression [28]. To more definitively identify HPV-associated OPSCC, multimodality HPV testing is increasing, with p16 IHC followed by HPV DNA PCR or in-situ hybridization (ISH) being the most common approaches [29]. In the UK, the National Institute for Health and Care Excellence (NICE) recommends reflexing to high-risk HPV DNA or RNA ISH in all p16-positive OPSCCs [30]. Because the specificity of HPV DNA PCR (87\%) and ISH (88\%) exceed that of p16, the use of these tests in tandem results in increased sensitivity and specificity for HPV detection as opposed to single-modality testing [26]. In addition,
HPV DNA testing is being used to diagnose cancer from fine needle aspirates from cervical lymph nodes and to help identify primary tumors [31]. However, the technical challenges and costs of HPV DNA PCR or ISH have limited their use for initial screening.

Next-generation sequencing (NGS) has emerged as an exciting new technology with the potential to identify $\mathrm{HPV}(+)$ tumors and provide rich mechanistic and prognostic information distinguishing subsets even within the $\mathrm{HPV}(+)$ group. A 2014 study using NGS found that $\mathrm{HPV}(+)$ tumors could be further categorized by presence of integrated versus nonintegrated HPV genes and that integration status corresponded with different patterns of DNA methylation and human and viral gene expression profiles in genes with known roles in carcinogenesis [32]. While implications of these findings are unknown, NGS will likely prove clinically useful in the future.

\section{Prognosis}

HPV-positive OPSCC carries a favorable prognosis compared to HPV-negative tumors. Five-year survival rates for patients with advanced stage $\mathrm{HPV}(+)$ OPSCC are $75-80 \%$, versus survival rates of less than $50 \%$ among patients with similarly staged $\mathrm{HPV}(-)$ tumors [33]. The improved survival of patients with $\mathrm{HPV}(+)$ tumors can in part be attributed to their remarkable treatment sensitivity, as $\mathrm{HPV}(+)$ tumors have been shown to respond better to chemotherapy and radiation than HPV(-) tumors $[16,34]$. The better prognosis conferred by HPV positivity is reflected in the updated AJCC 8th edition staging system, which for the first time separates staging for $\mathrm{HPV}(+)$ and $\mathrm{HPV}(-)$ OPSCCs and in general downgrades $\mathrm{HPV}(+)$ OPSCC staging [24, 35]. For example, $\mathrm{HPV}(+)$ OPSCC T3 N2, which was classified as Stage IVA in AJCC 7th edition, is newly classified as clinical Stage II in AJCC 8th edition.

Interest in identifying prognostic biomarkers in $\mathrm{HPV}$-associated OPSCC has stemmed from the desire to decrease treatment morbidity while maintaining high cure rates. While a positive $\mathrm{p} 16$ by IHC predicts a favorable prognosis regardless of HPV status, recent data has shown that when used together with HPV status, further prognostic stratification is achieved [36]. A 2017 meta-analysis of both OPSCC and HNSCC patients found that the 5-year overall survival was best for patients with $\mathrm{HPV}(+) / \mathrm{p} 16(+)$ tumors, intermediate for $\mathrm{HPV}(-) / \mathrm{p} 16(+)$ tumors, and worst for $\mathrm{HPV}(+) / \mathrm{p} 16(-)$ and $\operatorname{HPV}(-) / \mathrm{p} 16(-)$ tumors [37].

Recent analysis of an HNSCC cohort in The Cancer Genome Atlas (TCGA) identified potential molecular biomarkers that can be used for prognostication [38, 39]. Deletion or mutation of two proteins that inhibit NF-kB and activate interferon, TNF receptor-associated factor 3 (TRAF3) and cylindromatosis (CYLD), were found in 
$28 \%$ of HPV(+) OPSCC [38]. Remarkably, survival for patients with $\mathrm{HPV}(+)$ tumors was better for those whose tumors carried defects in either TRAF3 or CYLD, while survival of $\mathrm{HPV}(+)$ patients without these mutations was similar to that of $\mathrm{HPV}(-)$ negative patients [38].

\section{Treatment}

Despite the prognostic significance of HPV in HNSCC, HPV status has not altered treatment guidelines. For the first time in 2018, The National Comprehensive Cancer Network Clinical Practice Guidelines in Oncology (NCCN, USA), separated treatment pathways for p16(+) and p16(-) OPSCCs [24]; however, recommendations for p16(+) and p16(-) OPSCCs are almost identical, with the only notable difference as follows: as an alternative to definitive radiation therapy (RT) alone or surgery alone, treatment with RT plus systemic therapy is a recommendation (category 2B) for T1 N1 p16-negative tumors, but is not recommended for p16-positive tumors until tumor size reaches T2 (with single node $\leq 3 \mathrm{~cm}$ ). In general, regardless of p16 status, RT or surgery remain recommended treatment modalities for early-stage tumors, and combined therapy is recommended for advanced stages. The benefits of induction chemotherapy before concurrent chemoradiation are still being studied, with a recent meta-analysis demonstrating no survival advantage with induction chemotherapy [40].

Standard therapy for advanced OPSCC regardless of HPV status as either definitive or post-operative therapy includes chemotherapy and radiation, which is associated with dose-related adverse side effects, from acute toxicities like mucositis and loss of taste to long-term problems including dysphagia, renal dysfunction, hearing loss, xerostomia, osteoradionecrosis, accelerated arteriosclerosis, neck muscle fibrosis, and trismus. These side effects can lead to a cascade of events, including infections, difficulty eating, and increased hospitalizations, that can markedly erode quality of life. Based on analysis of long-term survivors from the RTOG 91-11 clinical trial, there is also the possibility that treatment-associated morbidity may impact 10 -year or longer survival [41]. Given these concerns, minimizing side effects is especially important in advancing therapy for $\mathrm{HPV}(+)$ patients, who present at a younger age and have improved survival compared to patients with HPV(-) disease $[11-13,16]$.

The distinct tumor biology, higher treatment sensitivity, and better prognosis of $\mathrm{HPV}(+)$ OPSCCs has piqued interest in therapies that can minimize side effects, including new treatment approaches and de-escalation of current therapies. A single-arm phase II clinical trial, ECOG 1308, examined if response to induction chemotherapy could select stage III-IV (AJCC 7th edition) $\mathrm{HPV}(+)$ OPSCC patients for reduced-dose radiation
[42]. This trial found that patients with complete response to induction therapy maintained expected tumor control with reduced radiation doses of 54 Gy (compared to $69.3 \mathrm{~Gy}$ ) but had fewer swallowing problems and nutritional deficiencies. A similar single institution trial also used induction chemotherapy, but stratified $\mathrm{HPV}(+)$ OPSCC patients to lower dose radiation (54.Gy) with similar survival and side effect findings [43]. The limited size of both studies as well as the recent changes to the AJCC staging criteria suggest the need for additional larger trials as are currently being considered through the National Clinical Trials Network (NCTN).

Several clinical trials (see Table 1 for currently active or recently completed clinical trials in HPV-associated OPSCC) are examining de-escalated treatments for $\mathrm{HPV}(+)$ OPSCCs, include reduced-dose radiation and/or chemotherapy (NCT03215719, NCT03323463, NCT01706939, NCT01898494, NCT02281955, NCT02048020, NCT02215265, NCT02048020), stratifying by responsiveness to induction chemotherapy to select subsequent loco-regional therapy (NCT02281955, NCT03107182), efficacy of chemotherapy or radiation as alternatives to surgery (NCT03210103, NCT03342911), minimally-invasive transoral robotic surgery using pathology to stratify patients for de-escalation (NCT02225496), treatment with surgery alone (NCT02072148), and using targeted therapies (NCT03 260023, NCT01855451, NCT02002182, NCT03410615, NCT02540928, NCT03342911).

In addition to de-escalation of standard therapy, new treatment modalities for HPV+ HNSCC are being developed with the hope of decreasing morbidity of current therapies. Early promising results from an ongoing clinical trial published in 2017 from the Yale Cancer Center examined molecular effects of DNA-demethylation using 5-azacytidine (5-azaC) for treatment of $\mathrm{HPV}(+)$ HNSCC patients [44], Table 1. Preclinical data revealed that 5-azaC inhibits growth and increases cell death of $\mathrm{HPV}(+)$ cancer cells associated with reduced expression of HPV genes, stabilization of p53, and activation of p53-dependent apoptosis. Evaluation of $\mathrm{HPV}(+)$ OPSCC tumor specimens from trial patients treated with 5 -azaC $\left(75 \mathrm{mg} / \mathrm{m}^{2}\right.$ for $5-7$ days $)$ reinforced the pre-clinical data, showing increased p53 expression, increased apoptosis and decreased expression of HPV genes. In a mouse xenograft model, 5-aza was also found to reduce the metastatic potential of $\mathrm{HPV}(+)$ tumors. A larger clinical trial is needed to fully characterize the therapeutic potential and safety of this promising therapy in $\mathrm{HPV}(+) \mathrm{HNSCC}$.

One mechanism of immune escape in HNSCCs is mediated by the receptor programmed death -1 (PD-1) interacting with its ligand, PD-L1, which is expressed in $50-60 \%$ of HNSCC and 70\% of HPV(+) HNSCCs [45]. PD-L1, found to be selectively expressed in tonsillar 
Table 1 displays currently active or recently completed clinical trials in HPV-associated OPSCC (adapted from https:// clinicaltrials.gov)

\begin{tabular}{|c|c|c|c|}
\hline & NCT Number & Title & Interventions \\
\hline 1 & NCT03656133 & $\begin{array}{l}\text { Use of a Proliferation Saturation Index to Determine Personalized } \\
\text { Radiotherapy for HPV + Oropharyngeal Cancers }\end{array}$ & - Radiotherapy fractionation \\
\hline 2 & NCT03618134 & $\begin{array}{l}\text { Stereotactic Body Radiation Therapy and Durvalumab With or } \\
\text { Without Tremelimumab Before Surgery in Treating Participants } \\
\text { With Human Papillomavirus Positive Oropharyngeal Squamous Cell } \\
\text { Caner }\end{array}$ & $\begin{array}{l}\text { - Durvalumab } \\
\text { - Modified Radical Neck Dissection } \\
\text { - Transoral Robotic Surgery } \\
\text { - Tremelimumab }\end{array}$ \\
\hline 3 & NCT03580070 & $\begin{array}{l}\text { Changes in the Microenvironment of HPV-induced Head and Neck } \\
\text { Cancers in West Indies and Metropolitan Population }\end{array}$ & •Immunotherapy \\
\hline 4 & NCT03578406 & $\begin{array}{l}\text { HPV-E6-Specific TCR-T Cells in the Treatment of HPV-Positive } \\
\text { NHSCC or Cervical Cancer }\end{array}$ & - HPV E6-specific TCR-T cells \\
\hline 5 & NCT03418480 & HPV Anti-CD40 RNA Vaccine & - HPV vaccine \\
\hline 6 & NCT03396718 & $\begin{array}{l}\text { De-escalation of Adjuvant Radio (Chemo) Therapy for HPV-positive } \\
\text { Head-neck Squamous Cell Carcinomas }\end{array}$ & $\begin{array}{l}\text { - De-escalation radio(chemo)therapy } \\
\text { - Levels } 1 \text { and } 2\end{array}$ \\
\hline 7 & NCT03342911 & $\begin{array}{l}\text { Nivolumab, Carboplatin, and Paclitaxel in Treating Patients With Stage III-IV } \\
\text { Head and Neck Squamous Cell Carcinoma That Can Be Removed by } \\
\text { Surgery }\end{array}$ & - Paclitaxel, Carboplatin, Nivolumab \\
\hline 8 & NCT03260023 & $\begin{array}{l}\text { Phase Ib/II of TG4001 and Avelumab in HPV16 Positive R/M Cancers and } \\
\text { Expansion Cohort to Oropharyngeal SCCHN }\end{array}$ & - TG4001, Avelumab \\
\hline 9 & NCT03224000 & $\begin{array}{l}\text { Trial of Magnetic Resonance Imaging Guided Radiotherapy Dose } \\
\text { Adaptation in Human Papilloma Virus Positive Oropharyngeal Cancer }\end{array}$ & $\begin{array}{l}\text { - Modified Barium Swallow, MRI } \\
\text { Guided Intensity Modulated Radiotherapy }\end{array}$ \\
\hline 10 & NCT03162224 & $\begin{array}{l}\text { Safety and Efficacy of MEDI0457 and Durvalumab in Patients With } \\
\text { HPV Associated Recurrent/Metastatic Head and Neck Cancer }\end{array}$ & $\begin{array}{l}\text { - MEDI0457, CELLECTRA } 5 \text { PP } \\
\text { device, Durvalumab }\end{array}$ \\
\hline 11 & NCT03107182 & $\begin{array}{l}\text { Chemotherapy and Locoregional Therapy Trial (Surgery or } \\
\text { Radiation) for Patients With Head and Neck Cancer }\end{array}$ & $\begin{array}{l}\text {-Carboplatin, Nivolumab, Cisplatin, Hydroxyurea, 5- } \\
\text { FU, Dexamethasone, Famotidine, Diphenhydramine, } \\
\text { Paclitaxel }\end{array}$ \\
\hline 12 & NCT03077243 & $\begin{array}{l}\text { P53 Mutational Status and cf HPV DNA for the Management of } \\
\text { HPV-associated OPSCC }\end{array}$ & $\begin{array}{l}\text { - Intensity Modulated Radiotherapy, } \\
\text { Cisplatin (or alternative) }\end{array}$ \\
\hline 13 & NCT02945631 & $\begin{array}{l}\text { Quarterback } 2 \text { - Sequential Therapy With Reduced Dose } \\
\text { Chemoradiotherapy for HPV Oropharynx Cancer }\end{array}$ & - Radiation: PTV56 \\
\hline 14 & NCT02865135 & $\begin{array}{l}\text { Trial To Test Safety And Efficacy Of Vaccination For Incurable HPV } \\
\text { 16-Related Oropharyngeal, Cervical And Anal Cancer }\end{array}$ & - DPX-E7 vaccine \\
\hline 15 & NCT02827838 & $\begin{array}{l}\text { Durvalumab Before Surgery in Treating Patients With Oral Cavity or } \\
\text { Oropharynx Cancer }\end{array}$ & - Durvalumab \\
\hline 16 & NCT02784288 & $\begin{array}{l}\text { Phase II Treatment Stratification Trial Using Neck Dissection-Driven } \\
\text { Selection to Improve Quality of Life for Low Risk Patients With HPV } \\
\text { + Oropharyngeal Squamous Cell Cancer }\end{array}$ & - Radiation, Carboplatin, Paclitaxel \\
\hline 17 & NCT02706691 & $\begin{array}{l}\text { BGJ398 in Treating Patients With FGFR Positive Recurrent Head and Neck } \\
\text { Cancer }\end{array}$ & •BGJ398 \\
\hline 18 & NCT02686008 & $\begin{array}{l}\text { Pharmacodynamic Study to Assess the Anti-proliferative Activity of the } \\
\text { PARP Inhibitor Olaparib in Patients With HPV Positive and HPV Negative } \\
\text { HNSCC }\end{array}$ & - Olaparib \\
\hline 19 & NCT02643550 & $\begin{array}{l}\text { Study of Monalizumab and Cetuximab in Patients With Recurrent or } \\
\text { Metastatic Squamous Cell Carcinoma of the Head and Neck }\end{array}$ & - Monalizumab, Cetuximab \\
\hline 20 & NCT02281955 & $\begin{array}{l}\text { De-intensification of Radiation and Chemotherapy for Low-Risk } \\
\text { HPV-related Oropharyngeal SCC: Follow-up Study }\end{array}$ & - Radiation, cisplatin \\
\hline 21 & NCT02215265 & $\begin{array}{l}\text { Post-operative Adjuvant Treatment for HPV-positive Tumours } \\
\text { (PATHOS) }\end{array}$ & - Cisplatin, Postoperative radiotherapy \\
\hline 22 & NCT02178072 & Window Trial 5-aza in HNSCC, T-tare & - 5-Azacitadine \\
\hline 23 & NCT02113878 & $\begin{array}{l}\text { Phase Ib Study of BKM120 With Cisplatin and XRT in High Risk } \\
\text { Locally Advanced Squamous Cell Cancer of Head and Neck }\end{array}$ & - BKM120, Cisplatin, Intensity-modulated radiotherapy \\
\hline 24 & NCT02002182 & $\begin{array}{l}\text { ADXS 11-001 Vaccination Prior to Robotic Surgery, HPV-Positive } \\
\text { Oropharyngeal Cancer }\end{array}$ & - ADXS11-001 (ADXS-HPV) \\
\hline 25 & NCT01716195 & $\begin{array}{l}\text { Induction Chemotherapy Followed by Chemoradiotherapy for Head and } \\
\text { Neck Cancer }\end{array}$ & - Radiotherapy \\
\hline
\end{tabular}


Table 1 displays currently active or recently completed clinical trials in HPV-associated OPSCC (adapted from https:// clinicaltrials.gov) (Continued)

\begin{tabular}{llll}
\hline NCT Number & Title & Interventions \\
\hline 26 NCT01706939 & $\begin{array}{l}\text { The Quarterback Trial: Reduced Dose Radiotherapy for HPV+ Oropharynx } \\
\text { Cancer }\end{array}$ & • Reduced Dose Radiation, Carboplatin \\
27 NCT01530997 & $\begin{array}{l}\text { De-intensification of Radiation \& Chemotherapy in Low-Risk Human } \\
\text { Papillomavirus-related Oropharyngeal Squamous Cell Ca }\end{array}$ & •Intensity Modulated Radiotherapy, Cisplatin \\
28 NCT01302834 & $\begin{array}{l}\text { Radiation Therapy With Cisplatin or Cetuximab in Treating Patients } \\
\text { With Oropharyngeal Cancer }\end{array}$ & $\cdot$ cetuximab, cisplatin \\
\hline
\end{tabular}

crypts, may facilitate HPV infection at these sites, reflecting the potential for targeted therapy with PD-1 inhibitors in $\mathrm{HPV}(+)$ cancers [46]. Two PD-1 inhibitors, pembrolizumab (KEYTRUDA, Merck Sharp \& Dohme) and nivolumab (OPDIVO, Bristol-Myers Squibb), were approved by the FDA for the treatment of recurrent or metastatic HNSCC that failed a platinum-based therapy $[47,48]$. Studies examining the efficacy of these drugs in patients with recurrent or metastatic HNSCC revealed a relatively low overall response rate of $13-18 \%$ with no difference in response between $\mathrm{HPV}(+)$ and $\mathrm{HPV}(-)$ cancers [45]. Many clinical trials examining combinations of immune checkpoint inhibitors with other immune modulators, radiation, cytotoxic chemotherapy or epigenetic therapies are underway [49].

\section{Molecular characteristics}

In addition to the epidemiological, pathological, and clinical characteristics distinguishing $\mathrm{HPV}(+)$ and $\mathrm{HPV}(-)$ OPSCCs, TCGA and other efforts have elucidated molecular and epigenetic differences [50-52]. Here, we will explore heterogeneity between $\mathrm{HPV}(+)$ and $\mathrm{HPV}(-)$ HNSCC, as well as distinctions within OPSCC driven by HPV with particular attention on defects that correlate with tumor response and patient survival.

Altered DNA-repair pathways, differences in mitogenic signaling pathways, dysregulation of cell cycle control, and changes in the tumor micro-environment of $\mathrm{HPV}(+)$ tumors have all been proposed as possible explanations of their enhanced sensitivity to radiation [53]. SMG-1 (suppressor with morphogenetic effect on genitalia) is a member of the phosphoinositide 3-kinase-related kinases (PIKK) family and plays an important role in the DNA-damage response [54-56]. In OPSCCs, expression of SMG-1 was found to be decreased in $\mathrm{HPV}(+)$ tumors due to hypermethylation of its promotor [57]. This decreased expression of SMG-1 appears to be an important contributor to the radiosensitivity of $\mathrm{HPV}(+)$ cells, as depletion of SMG-1 in $\mathrm{HPV}(-)$ cells was shown to cause increased radiosensitivity while overexpression in $\mathrm{HPV}(+)$ protected cells from radiation [57]. Further evidence of the altered mechanisms in DNA repair in $\mathrm{HPV}(+)$ tumors was seen through reverse-phase protein array (RPPA) profiling of OPSCCs, which found that all eleven DNA repair proteins screened, including BRCA2, MSH2, PARP-1, and ATM, were significantly upregulated in $\mathrm{HPV}(+)$ samples compared to $\mathrm{HPV}(-)$ samples [58]. This is particularly interesting, since $\mathrm{HPV}(+)$ oropharyngeal cancer cells have shown a partial deficiency in DNA double strand breaks repair mostly in the homologous recombination repair pathway $[59,60]$ that may also contribute to increased sensitivity to radiation or DNA damaging agents.

Differences in cell cycle regulation may also play a role in the remarkable treatment sensitivity of $\mathrm{HPV}(+)$ tumors. Amplification and overexpression of cyclin D1, inactivation of the cyclin-dependent kinase inhibitor p16, and mutations of the tumor suppressor p53 are common defects found in $\mathrm{HPV}(-) \mathrm{HNSCC}$, but are lacking in $\mathrm{HPV}(+)$ tumors [50, 61]. On the other hand, amplification and overexpression of E2F1, which is a driver of G1-to-S transition, is common in $\mathrm{HPV}(+)$ but not HPV(-) HNSCC [50, 61]. Given these differences in cell cycle regulation, it is not surprising that differences to treatment with cyclin-dependent kinase (CDK) inhibitors are observed. HPV-positivity has been shown to correlate with hypersensitivity of tumor cells to roscovitine, a cyclin-dependent kinase (CDK) inhibitor that inhibits CDK-1, 3, 5, 7, and 9 [62]. Treatment of HPV(+) OPSCC cells with roscovitine resulted in DNA-damage and induced a p53-dependent cell death [62]. Additionally, low-doses of roscovitine that did not cause weight loss in mice significantly inhibited growth of $\mathrm{HPV}(+)$ xenografted tumors.

In addition to differences distinguishing $\mathrm{HPV}(+)$ and $\mathrm{HPV}(-)$ head and neck tumors, significant molecular heterogeneity exists within $\mathrm{HPV}(+)$ tumors themselves. Gene expression profiling has classified $\mathrm{HPV}(+)$ tumors into two subgroups with one (HPV-KRT) having elevated expression of genes involved in keratinization, viral integrations, spliced E6, chr3q amplifications, and PIK3CA mutations, and the other subgroup (HPV-IMU) having more mesenchymal differentiation, full-length E6 activity, chr16q deletions, and a stronger immune response [63]. Although TCGA survival analysis showed a trend toward better survival in the HPV-IMU subgroup, the survival difference was not significant, warranting further investigation into the clinical implications of this $\mathrm{HPV}(+)$ stratification model [63].

Further proving the heterogeneity of $\mathrm{HPV}(+) \mathrm{HNSCCs}$, a 2014 study of HNSCCs from TCGA found that of the 35 
$\mathrm{HPV}(+)$ tumors, 25 had integration of the viral genome while 10 tumors lacked integration [32]. The canonical paradigm of HPV carcinogenesis, which was developed through studies of uterine cervical cancer, highlights the importance of HPV genome integration as premalignant lesions transition to become malignant [64]. Discovering that nearly $30 \%$ of $\mathrm{HPV}(+)$ OPSCC contained only episomal HPV challenged this canonical theory of HPV carcinogenesis and presented an opportunity for understanding alternative mechanisms of HPV-driven tumorigenic conversion.

OPSCC with integrated versus nonintegrated HPV have differences in somatic gene methylation, gene expression patterns, mRNA processing, and inter- and intrachromosomal rearrangements [32]. For tumors with HPV integration, integration was not random, with many integration sites occurring within cancer-associated genes suggesting that even within tumors with integrated HPV, different molecular events may be involved in carcinogenesis [32, 65]. Given the molecular differences that are based on HPV integration status, it is not surprising that clinical parameters also differ. In support of this, absence of integration correlated with improved survival and with indications of increased immune infiltration [65]. Recently, defects in TRAF3 and CYLD were found as novel alterations in HNSCC that identified a subset of $\mathrm{HPV}(+)$ HNSCC with improved survival $[38,50]$. TRAF3 and CYLD gene deletions or disruptive mutations were identified in $28 \%$ of $\mathrm{HPV}(+)$ specimens in the initial TCGA HNSCC cohort and correlated with the absence of HPV gene integration [38]. Consistent with known functions of TRAF3 and CYLD, tumors with altered TRAF3 or CYLD had activation of NF-kB and inactivation of innate immune signaling $[38,39]$. These gene defects were nearly significant in correlating with decreased tobacco exposure in this cohort, raising the possibility that DNA damage, reactive oxygen species or other factors associated with tobacco smoke may increase the probability of HPV integration. In light of finding that TRAF3 or CYLD mutation or deletion identified a unique subset of $\mathrm{HPV}(+)$ patients, additional analysis of genes regulating the NF- $k B$ pathway were examined in an independent Yale cohort (unpublished data). This analysis confirmed the existence of TRAF3 and CYLD mutations, but also found defects in additional NF-kB regulators (MAP3K14, BIRC3, TRAF2, and MYD88). This cohort is being followed, but time from treatment for this cohort is currently too short to draw survival conclusions. Identification of additional mutations in regulators of NF-kB suggest that NF-kB pathway defects in addition to TRAF3 and CYLD may be important for separating subtypes of $\mathrm{HPV}(+)$ OPSCC tumors.

\section{Etiology}

The mechanisms of HPV-driven OPSCC have not been intensely studied, as many have assumed that HPV carcinogenesis in OPSCC is identical to the accepted mechanism of HPV carcinogenesis in the uterine cervix; however, there are many differences between $\operatorname{HPV}(+)$ OPSCC and uterine cervical cancer. HPV $(+)$ OPSCC and cervical cancer diverge in epidemiologic factors, molecular patterns, HPV type, mutational profile, cell-of-origin, treatment response, and clinical behavior (Table 2), suggesting that uterine cervical cancer and OPSCC are distinct [66]. While more than $85 \%$ of cervical cancer cases worldwide are from developing nations, the developing world has relatively fewer OPSCCs than higher-income countries [66]. Furthermore, over 90\% of HPV(+) OPSCCs are caused by HPV16, whereas in cervical cancer, only $50 \%$ is attributable to HPV 16 and up to $20 \%$ is caused by HPV18, which is rarely identified in OPSCC $[14,67]$. $\mathrm{HPV}(+)$ OPSCC and uterine cervical cancer mutational landscapes also differ; for example, in an analysis of an expanded TCGA cohort, almost 30\% of HPV(+) oropharyngeal tumors had TRAF3 or CYLD mutations or deletions, while these mutations were extremely rare in cervical cancer [38]. From a clinical standpoint, HPV(+) OPSCCs respond better to treatment than $\mathrm{HPV}(+)$ cervical cancer, possibly due to differences in the unique properties of their respective epithelial sites of infection, clinical presenting signs and symptoms, patterns of metastasis, and target populations, but also possibly due to molecular differences [66]. Clinical and molecular differences between OPSCC and uterine cervical cancer should caution against equating any aspect of these HPV-associated diseases including carcinogenesis, treatment response or outcome.

The productive HPV life cycle has been studied and is outlined here [68]. In the uterine cervix, HPV gains access through microabrasions to infect basal epithelial cells, and after infection, the HPV genome replicates to a low copy number to be maintained as nuclear episomes. HPV early genes are expressed at low levels, and after the initial low-level amplification, HPV episomes are maintained through replication in sync with cell division. These characteristics are thought to assist with immune evasion by minimizing activation of pattern recognition receptors, $\mathrm{NF}-\mathrm{kB}$, and downstream type I interferon signaling. Emphasizing the importance of immune system evasion in HPV life cycle, proteins encoded by HPV inhibit NF-kB and type I interferon signaling [69]. Cellular differentiation is critical for the final productive amplification stage of the HPV life cycle. As cells migrate toward the surface of the epithelium, differentiation triggers increased expression of E6 and E7 oncoproteins that in turn enables an expansion of DNA replication-competent cells and a several log amplification of HPV episomes, ultimately concluding with expression of late viral capsid genes, encapsidation of HPV genomes, and shedding of new viral particles from the epithelial surface $[70,71]$. Most mucosal infections are cleared within two years through activation of innate and 
Table 2 Major differences between cervical cancer and HPV-associated OPSCC

\begin{tabular}{lll}
\hline & OPSCC & Cervical Cancer \\
\hline Incidence & Incidence increasing & Incidence decreasing \\
Prevalence & Increased in higher-income countries & Increased in lower-income countries \\
Sex & $>70 \%$ male & $100 \%$ female \\
Etiology & Tobacco and alcohol remain important & Virtually all are caused by HPV \\
& causes, along with HPV & $50 \%$ HPV16 \\
HPV genotype & $>95 \%$ HPV16 & $20 \%$ HPV18 \\
Premalignant lesions & HPV18 rare & CIN1-3 \\
Screening tests available & Unknown & Yes \\
5-year survival rate & No & $<70 \%$ \\
TRAF3/CYLD mutations & $>75 \%$ & Rare \\
Treatment sensitivity to chemotherapy and radiation & Approximately 30\% & Moderate \\
\hline
\end{tabular}

acquired immune mechanisms [72, 73]. The importance of acquired immunity in HPV clearance is supported by identification of HLA variants associated with decreased risk of both $\mathrm{HPV}(+)$ OPSCC and uterine cervical cancer [74]. On the other hand, persistent infection predisposes to malignant transformation that requires additional mutations and/or immune deficiency. The delay between HPV infection and detection of malignancy can be several decades $[17,70]$.

Studies of the transformation process initiated by HPV infection have relied heavily on the study of premalignant uterine cervical cells and have led to a canonical model of HPV carcinogenesis. In this model, initial infection, establishment and maintenance are thought to parallel the normal HPV life cycle; however, with persistent infection of basal or stem cells carcinogenesis can be initiated. The model details that as cells progress from early dysplasia (CIN1) to pre-malignant lesions (CIN3), the HPV genome integrates and disrupts the HPV E2 gene, which relieves negative feedback and increases expression of HPV oncoproteins, E6 and E7 [72, 75-77]. As opposed to the natural life cycle where E6 and E7 expression increases in the superficial layers of the epithelia, the carcinogenesis model establishes cells with high E6 and E7 expression at the basal layer of the epithelium where in the absence of immune clearance, these pre-malignant cells persist. Increased expression of HPV oncoproteins inactivates the major human tumor suppressor genes, p53 and RB leading to genomic instability, resistance to apoptosis, and dysregulated cell cycle control. One caveat of integration studies that contributed to the model is that methods for identification of integrated HPV frequently relied on loss of E2, and by design, these techniques exclude integrated forms that maintain E2 [77]. While integration of the HPV genome is part of the canonical HPV carcinogenesis model, it excludes a percentage of HPV type 16-positive cervical cancers that lack detected HPV integration [77]. It is unclear if this model applies to a portion of OPSCC with integration, but it is evident that it does not describe carcinogenesis for $\mathrm{HPV}(+)$ OPSCC that lack integration of the HPV genome.

TCGA analysis of HPV-associated OPSCC provides some characterization of the role of HPV integration in tumors [32]. Genomic profiling revealed that HPV-driven carcinogenesis is more complex and heterogeneous than previously thought. In OPSCC, HPV integration was associated with breakpoints throughout the viral genome, with only breakpoints in E1 occurring more frequently than expected by chance. This finding contrasts with the canonical HPV carcinogenesis model, in which disruption of E2 through integration leads to enhanced expression of E6 and E7 [72]. Further complicating the picture, whole genome sequencing data identified a category of tumors containing both partially deleted HPV genomes and full-length genomes [78]. The status of HPV in these "mixed" tumors remains controversial, with some authors describing these tumors as containing both integrated and nonintegrated HPV, while others argue that these tumors represent viral-human hybrid episomes [79].

Direct analysis of the HPV carcinogenesis process in the tonsil is not possible due to the absence of a defined pre-malignant lesion. The area infected by HPV and prone to transformation within the tonsil - the tonsillar crypt lacks tight epithelial junctions and is characterized by incomplete basement membranes making pathological distinction between invasive cancer and intra-epithelial neoplasia impossible $[80,81]$. In fact, the College of American Pathologists 2017 Guidelines state that in-situ disease in $\mathrm{HPV}(+)$ oropharyngeal cancer is "non-existent" [82]. In addition, murine modeling of OPSCC may not recreate the human situation because mice do not have tonsils and therefore lack the tonsillar crypt cells that are the target of carcinogenic HPV infection. 
Given the difficulties of studying progression of HPV pre-malignancies in the oropharynx, comparison of molecular characteristics of OPSCC and uterine cervical cancer may shed light on mechanisms of carcinogenesis in these distinct cancers. APOBEC (apolipoprotein B mRNA editing enzyme, catalytic polypeptide-like) is a cytidine deaminase whose mutations have been implicated in carcinogenesis. Both OPSCC and uterine cervical cancers have enrichment for APOBEC mutational signatures [50, 83, 84]. Consistent with finding APOBEC mutational signatures in each, both tumor types have a significant burden of APOBEC-driven PIK3CA mutations, and activating mutations of PI3KCA occur more frequently in $\operatorname{HPV}(+)$ than $\operatorname{HPV}(-)$ OPSCCs $[50,58,84]$. Enhanced PI3K signaling has been implicated in HNSCC tumorigenesis; however, the role of PI3K pathway activation by PIK3CA mutations in $\mathrm{HPV}(+)$ OPSCC needs to be further explored since AKT was not activated by mutant PIK3CA in the presence of HPV oncoproteins [58, 85, 86]. Cervical cancers and OPSCCs also share an absence of mutations in genes or pathways regulated by HPV oncoproteins such as p53 and p16 ${ }^{\mathrm{INK} 4 \mathrm{a}}$, confirming the importance of HPV oncogenes in tumorigenesis [50, 84]. Interestingly, EGFR (17\%) and ERB2 (17\%) amplifications were found in uterine cervical cancer, but not in $\mathrm{HPV}(+)$ OPSCC, while FGFR3 amplifications were found in $11 \%$ of $\operatorname{HPV}(+)$ OPSCC, but not in uterine cervical cancer, suggesting that these tumors rely differently on receptor tyrosine kinase signaling [50, 84].

For tumors caused by HPV type 16, integration of the HPV genome occurs at similar rates in OPSCC (72\%) and cervical cancer $(76 \%)[32,84]$. Despite the similar proportion of tumors lacking integration, the strong correlation of TRAF3 and CYLD defects with the absence of integration in OPSCC compared to the lack of these defects in uterine cervical cancer suggest that HPV carcinogenesis in tumors lacking integration may differ [38, 50, 84]. Although the reason for this difference is unknown, the function of TRAF3 and CYLD as inhibitors of NF-kB and activators of type I interferon signaling suggest that disruption of these genes may be critical for survival of infected cells and maintenance of unintegrated HPV DNA in oropharyngeal cells. A recent study confirmed that attenuated TRAF3 activated NF-kB and inhibited interferon in HPV $(+)$ HNSCC cells [87]. The reason that TRAF3 or CYLD mutations are not required in uterine cervical cells is unknown but could relate to the differences in the infected cell. Unlike uterine cervical cells at the squamocolumnar junction, tonsillar crypt cells are closely associated with non-epithelial and lymphatic cells [88]. The lymphoepithelium of the tonsil is critical for initiation of immune responses with one role of the specialized crypt epithelial cells being endocytosis to deliver antigens to adjacent immune cells that initiate immune responses through antigen processing and release of cytokines [88]. Several pathogens take advantage of the discontinuous epithelium and immune milieu to invade, including the Epstein-Barr Virus (EBV), which infects the lymphoepithelium of the nasopharynx and can result in nasopharyngeal cancer [88]. Like HPV, EBV infects many years before cancers develops and must be maintained for carcinogenic conversion. Unlike HPV, EBV is a herpesvirus, which does not integrate and therefore must be maintained in an episomal form [89]. Interestingly, EBV-associated nasopharyngeal cancer is one of the few solid tumor types other than $\mathrm{HPV}(+)$ OPSCC that has TRAF3 mutations $[38,90]$. Inhibition of NF-kB signaling in EBV-associated nasopharyngeal cancer cells has been shown to inhibit their growth, suggesting that the cells are reliant on continuous NF-kB activity [90].

Together these data raise the intriguing possibility of an alternative mechanism of HPV carcinogenesis uncovered through the study of $\mathrm{HPV}(+)$ OPSCC. Instead of HPV integration as a driver for increased oncoprotein expression, a subset of OPSCC may rely on maintenance of unintegrated HPV that in turn requires molecular defects in TRAF3, CYLD or other genes to activate NF-kB and inhibit innate immune responses.

\section{Conclusions}

Recent studies of OPSCC are increasing our understanding of HPV-associated carcinogenesis, including the possibility of an alternative mechanism reliant on activation of NF-kB, inhibition of interferon and maintenance of non-integrated $\mathrm{HPV}$. In addition, markers to identify $\mathrm{HPV}(+)$ OPSCC patients with improved prognosis are emerging. These insights are critical to improving our management of this rising disease and exploring effective new treatments and identification of patients for de-escalated therapy.

\section{Abbreviations}

5-azaC: 5-azacytidine; APOBEC: Apolipoprotein B mRNA editing enzyme, catalytic polypeptide-like; CDK: Cyclin-dependent kinase; CYLD: Cylindromatosis; EBV: Epstein-Barr Virus; HNSCC: Head and neck squamous cell carcinoma; HPV: Human papillomavirus; ISH: In-situ hybridization; NICE: National Institute for Health and Care Excellence; OPSCC: Oropharyngeal squamous cell carcinoma; PD-1: Programmed death - 1; PIKK: Phosphoinositide 3-kinase-related kinases; RPPA: Reverse-phase protein array; RT: Radiation therapy; SMG-1: Suppressor with morphogenetic effect on genitalia; TRAF3: TNF receptor-associated factor 3

\section{Acknowledgements}

The authors thank the Yale Department of Surgery, Otolaryngology Division; the Lineberger Cancer Center, and the UNC Department of Otolaryngology/ Head and Neck Surgery for support.

\section{Funding}

There was no funding for this review article; the financial support was provided by the Yale Department of Surgery Otolaryngology Division, the Lineberger Cancer Center, and the Deaprtment of Otolaryngology/Head and Neck Surgery at the University of North Carolina.

Availability of data and materials

This review article is original and has not been published elsewhere. 


\section{Authors' contributions}

$\mathrm{CP}$ searched literature. $\mathrm{CP}, \mathrm{NI}$, and WGY wrote the manuscript. All authors read and approved the final manuscript.

\section{Ethics approval and consent to participate} Not applicable.

\section{Consent for publication}

All authors consent for the publication of this review article.

\section{Competing interests}

The authors declare that they have no competing interest.

\section{Publisher's Note}

Springer Nature remains neutral with regard to jurisdictional claims in published maps and institutional affiliations.

\section{Author details}

'Department of Surgery, Division of Otolaryngology, Yale University, New Haven, CT, USA. ${ }^{2}$ Department of Otolaryngology/Head and Neck Surgery; Lineberger Cancer Center, University of North Carolina at Chapel Hill, 170 Manning Drive, Campus Box 7070, Chapel Hill, NC 27599, USA.

Received: 20 August 2018 Accepted: 9 December 2018 Published online: 29 December 2018

\section{References}

1. Dalla Torre D, Burtscher D, Soelder E, Offermanns V, Rasse M, Puelacher W Human papillomavirus prevalence in a mid-European oral squamous cell cancer population: a cohort study. Oral Dis. 2018;24:948-56.

2. Götz C, Drecoll E, Straub M, Bissinger O, Wolff K-D, Kolk A. Impact of HPV infection on oral squamous cell carcinoma. Oncotarget. 2016;7:76704-12. https://doi.org/10.18632/oncotarget.12501.

3. Shiboski CH, Schmidt BL, Jordan RCK. Tongue and tonsil carcinoma: increasing trends in the U.S. population ages 20-44 years. Cancer. 2005;103:1843-9.

4. Frisch $M$, Hjalgrim $H$, Jaeger $A B$, Biggar RJ. Changing patterns of tonsillar squamous cell carcinoma in the United States. Cancer Causes Control CCC. 2000;11:489-95.

5. Mehta V, Yu G-P, Schantz SP. Population-based analysis of oral and oropharyngeal carcinoma: changing trends of histopathologic differentiation, survival and patient demographics. Laryngoscope. 2010;120: 2203-12. https://doi.org/10.1002/lary.21129.

6. Sturgis EM, Cinciripini PM. Trends in head and neck cancer incidence in relation to smoking prevalence. Cancer. 2007;110:1429-35. https://doi.org/ 10.1002/cncr.22963.

7. Chaturvedi AK, Engels EA, Pfeiffer RM, Hernandez BY, Xiao W, Kim E, et al. Human papillomavirus and rising oropharyngeal Cancer incidence in the United States. J Clin Oncol. 2011:29:4294-301. https://doi.org/10.1200/JCO. 2011.36.4596.

8. Steinau M, Saraiya M, Goodman MT, Peters ES, Watson M, Cleveland JL, et al. Human papillomavirus prevalence in oropharyngeal cancer before vaccine introduction, United States. Emerg Infect Dis. 2014;20:822-8.

9. Singhi AD, Westra WH. Comparison of human papillomavirus in situ hybridization and p16 immunohistochemistry in the detection of human papillomavirus-associated head and neck cancer based on a prospective clinical experience. Cancer. 2010;116:2166-73.

10. CDC - How Many Cancers Are Linked with HPV Each Year? https://www.cdc gov/cancer/hpv/statistics/cases.htm. Accessed 15 Mar 2018

11. Pytynia KB, Dahlstrom KR, Sturgis EM. Epidemiology of HPV-associated oropharyngeal cancer. Oral Oncol. 2014;50:380-6. https://doi.org/10.1016/j. oraloncology.2013.12.019.

12. Gillison ML. Current topics in the epidemiology of oral cavity and oropharyngeal cancers. Head Neck. 2007;29:779-92

13. Goon PKC, Stanley MA, Ebmeyer J, Steinsträsser L, Upile T, Jerjes W, et al. HPV \& head and neck cancer: a descriptive update. Head Neck Oncol. 2009:1:36.

14. Gillison ML, Koch WM, Capone RB, Spafford M, Westra WH, Wu L, et al. Evidence for a causal association between human papillomavirus and a subset of head and neck cancers. J Natl Cancer Inst. 2000;92:709-20.

15. Dahlstrom KR, Calzada G, Hanby JD, Garden AS, Glisson BS, Li G, et al. an evolution in demographics, treatment, and outcomes of oropharyngeal cancer at a major cancer center. Cancer. 2013;119:81-9. https://doi.org/10.1002/cncr.27727.

16. Chaturvedi AK, Engels EA, Anderson WF, Gillison ML. Incidence trends for human papillomavirus-related and -unrelated oral squamous cell carcinomas in the United States. J Clin Oncol Off J Am Soc Clin Oncol. 2008;26:612-9.

17. Gillison ML, Chaturvedi AK, Anderson WF, Fakhry C. Epidemiology of human papillomavirus-positive head and neck squamous cell carcinoma. J Clin Oncol. 2015;33:3235-42. https://doi.org/10.1200/JCO.2015.61.6995.

18. Gillison ML, Alemany L, Snijders PJF, Chaturvedi A, Steinberg BM, Schwartz $S$, et al. Human papillomavirus and diseases of the upper airway: head and neck cancer and respiratory papillomatosis. Vaccine. 2012;30(Suppl 5):F34-54.

19. Gillison ML, Broutian T, Pickard RKL, Tong Z, Xiao W, Kahle L, et al. Prevalence of oral HPV infection in the United States, 2009-2010. JAMA. 2012;307:693-703.

20. D'Souza G, Agrawal Y, Halpern J, Bodison S, Gillison ML. Oral sexual behaviors associated with prevalent Oral human papillomavirus infection. J Infect Dis. 2009;199:1263-9. https://doi.org/10.1086/597755.

21. Kjaer SK, Chackerian B, van den Brule AJ, Svare El, Paull G, Walbomers JM, et al. High-risk human papillomavirus is sexually transmitted: evidence from a follow-up study of virgins starting sexual activity (intercourse). Cancer Epidemiol biomark Prev Publ am Assoc Cancer res cosponsored am Soc Prev. Oncologia. 2001;10:101-6.

22. Clinician FAQs: CDC Recommendations for HPV Vaccine 2-Dose Schedule | Human Papillomavirus (HPV) | CDC. 2017. https://www.cdc.gov/hpv/hcp/2 dose/clinician-faq.html. Accessed 24 Feb 2018

23. Chaturvedi AK, Graubard BI, Broutian T, Pickard RKL, Tong Z-Y, Xiao W, et al. Effect of Prophylactic Human Papillomavirus (HPV) Vaccination on Oral HPV Infections Among Young Adults in the United States. J Clin Oncol. 2017;36: 262-7. https://doi.org/10.1200/JCO.2017.75.0141

24. DG Pfister, S Spencer. NCCN clinical practice guidelines in oncology: head and neck cancers (version 1. 2018). https://www.ncen.org/professionals/ physician gls/f guidelines.asp. Accessed 11 Feb 2018.

25. Thavaraj S, Stokes A, Guerra E, Bible J, Halligan E, Long A, et al. Evaluation of human papillomavirus testing for squamous cell carcinoma of the tonsil in clinical practice. J Clin Pathol. 2011;64:308-12. https://doi.org/10.1136/jcp. 2010.088450.

26. Schache AG, Liloglou T, Risk JM, Filia A, Jones TM, Sheard J, et al. Evaluation of human papilloma virus diagnostic testing in oropharyngeal squamous cell carcinoma: sensitivity, specificity, and prognostic discrimination. Clin Cancer Res. 2011;17:6262-71. https://doi.org/10.1158/1078-0432.CCR-11-0388.

27. Reed AL, Califano J, Cairns P, Westra WH, Jones RM, Koch W, et al. High frequency of p16 (CDKN2/MTS-1/INK4A) inactivation in head and neck squamous cell carcinoma. Cancer Res. 1996;56:3630-3.

28. Wasylyk B, Abecassis J, Jung AC. Identification of clinically relevant HPVrelated HNSCC: in p16 should we trust? Oral Oncol. 2013:49:e33-7. https://doi.org/10.1016/j.oraloncology.2013.07.014.

29. Bishop JA, Lewis JS, Rocco JW, Faquin WC. HPV-related squamous cell carcinoma of the head and neck: an update on testing in routine pathology practice. Semin Diagn Pathol. 2015;32:344-51. https://doi.org/10.1053/j.semdp.2015.02.013.

30. Cancer of the upper aerodigestive tract: assessment and management in people aged 16 and over | Guidance and guidelines | NICE. https://www. nice.org.uk/guidance/NG36/chapter/Recommendations\#hpvrelated-disease. Accessed 11 Feb 2018.

31. Baldassarri R, Aronberg R, Levi AW, Yarbrough WG, Kowalski D, Chhieng D. Detection and genotype of high-Risk human papillomavirus in fine-needle aspirates of patients with metastatic squamous cell carcinoma is helpful in determining tumor origin. Am J Clin Pathol. 2015;143:694-700. https://doi. org/10.1309/AJCPCZA4PSZCFHQ4.

32. Parfenov M, Pedamallu CS, Gehlenborg N, Freeman SS, Danilova L, Bristow CA, et al. Characterization of HPV and host genome interactions in primary head and neck cancers. Proc Natl Acad Sci. 2014;111:15544-9. https://doi. org/10.1073/pnas.1416074111.

33. Ang KK, Harris J, Wheeler R, Weber R, Rosenthal DI, Nguyen-Tân PF, et al. Human papillomavirus and survival of patients with oropharyngeal Cancer. N Engl J Med. 2010;363:24-35. https://doi.org/10.1056/NEJMoa0912217.

34. Fakhry C, Westra WH, Li S, Cmelak A, Ridge JA, Pinto H, et al. Improved survival of patients with human papillomavirus-positive head and neck squamous cell carcinoma in a prospective clinical trial. J Natl Cancer Inst. 2008:100:261-9. 
35. Amin MB, Edge S, Greene F, Byrd DR, Brookland RK, Washington MK, et al. In: AJCC, editor. Cancer Staging Manual. 8th ed: Springer International Publishing: 2017. www.springer.com/us/book/9783319406176. Accessed 27 Feb 2018.

36. Lewis JS, Thorstad WL, Chernock RD, Haughey BH, Yip JH, Zhang Q, et al. p16 positive oropharyngeal squamous cell carcinoma: an entity with a favorable prognosis regardless of tumor HPV status. Am J Surg Pathol. 2010; 34:1088-96. https://doi.org/10.1097/PAS.0b013e3181e84652.

37. Albers AE, Qian X, Kaufmann AM, Coordes A. Meta analysis: HPV and p16 pattern determines survival in patients with HNSCC and identifies potential new biologic subtype. Sci Rep. 2017;7:16715.

38. Hajek M, Sewell A, Kaech S, Burtness B, Yarbrough WG, Issaeva N. TRAF3/ CYLD mutations identify a distinct subset of human papillomavirusassociated head and neck squamous cell carcinoma. Cancer. 2017;123:177890. https://doi.org/10.1002/cncr.30570.

39. Pan C, Yarbrough WG, Issaeva N. Advances in biomarkers and treatment strategies for HPV-associated head and neck cancer. Oncoscience. 2018;5:140-1.

40. Budach W, Bölke E, Kammers K, Gerber PA, Orth K, Gripp S, et al. Induction chemotherapy followed by concurrent radio-chemotherapy versus concurrent radio-chemotherapy alone as treatment of locally advanced squamous cell carcinoma of the head and neck (HNSCC): a meta-analysis of randomized trials. Radiother Oncol J Eur Soc Ther Radiol Oncol. 2016;118:238-43.

41. Forastiere AA, Zhang Q, Weber RS, Maor MH, Goepfert H, Pajak TF, et al. Long-term results of RTOG 91-11: a comparison of three nonsurgical treatment strategies to preserve the larynx in patients with locally advanced larynx cancer. J Clin Oncol Off J Am Soc Clin Oncol. 2013;31:845-52.

42. Marur S, Li S, Cmelak AJ, Gillison ML, Zhao WJ, Ferris RL, et al. E1308: phase II trial of induction chemotherapy followed by reduced-dose radiation and weekly Cetuximab in patients with HPV-associated Resectable squamous cell carcinoma of the oropharynx- ECOG-ACRIN Cancer research group. J Clin Oncol Off J Am Soc Clin Oncol. 2017;35:490-7.

43. Chen AM, Felix C, Wang P-C, Hsu S, Basehart V, Garst J, et al. Reduced-dose radiotherapy for human papillomavirus-associated squamous-cell carcinoma of the oropharynx: a single-arm, phase 2 study. Lancet Oncol. 2017;18:80311. https://doi.org/10.1016/S1470-2045(17)30246-2.

44. Biktasova A, Hajek M, Sewell A, Gary C, Bellinger G, Deshpande HA, et al. Demethylation therapy as a targeted treatment for human papillomavirusassociated head and neck Cancer. Clin Cancer Res. 2017;23:7276-87. https:// doi.org/10.1158/1078-0432.CCR-17-1438.

45. Saleh K, Eid R, Haddad FG, Khalife-Saleh N, Kourie HR. New developments in the management of head and neck cancer - impact of pembrolizumab. Ther Clin Risk Manag. 2018;14:295-303.

46. Lyford-Pike S, Peng S, Young GD, Taube JM, Westra WH, Akpeng B, et al. Evidence for a role of the PD-1:PD-L1 pathway in immune resistance of HPV-associated head and neck squamous cell carcinoma. Cancer Res. 2013; 73:1733-41. https://doi.org/10.1158/0008-5472.CAN-12-2384.

47. Pembrolizumab (KEYTRUDA). https:/www.fda.gov/drugs/informationondrugs/ approveddrugs/ucm515627.htm. Accessed 21 Mar 2018.

48. Nivolumab for SCCHN. https://www.fda.gov/drugs/informationondrugs/ approveddrugs/ucm528920.htm. Accessed 21 Mar 2018.

49. ClinicalTrials.gov. https://www.clinicaltrials.gov/. Accessed 21 Mar 2018.

50. Cancer Genome Atlas Network. Comprehensive genomic characterization of head and neck squamous cell carcinomas. Nature. 2015;517:576-82.

51. Stransky N, Egloff AM, Tward AD, Kostic AD, Cibulskis K, Sivachenko A, et al. The mutational landscape of head and neck squamous cell carcinoma. Science. 2011;333:1157-60.

52. Agrawal N, Frederick MJ, Pickering CR, Bettegowda C, Chang K, Li RJ, et al. Exome sequencing of head and neck squamous cell carcinoma reveals inactivating mutations in NOTCH1. Science. 2011;333:1154-7. https://doi.org/10.1126/science.1206923.

53. Mirghani H, Amen F, Tao Y, Deutsch E, Levy A. Increased radiosensitivity of HPV-positive head and neck cancers: molecular basis and therapeutic perspectives. Cancer Treat Rev. 2015;41:844-52. https://doi.org/10.1016/j.ctrv. 2015.10.001

54. Brumbaugh KM, Otterness DM, Geisen C, Oliveira V, Brognard J, Li X, et al. The mRNA surveillance protein hSMG-1 functions in genotoxic stress response pathways in mammalian cells. Mol Cell. 2004;14:585-98. https://doi.org/10.1016/j.molcel.2004.05.005.

55. Gewandter JS, Bambara RA, O'Reilly MA. The RNA surveillance protein SMG1 activates p53 in response to DNA double-strand breaks but not exogenously oxidized mRNA. Cell Cycle. 2011;10:2561-7. https://doi.org/10. 4161/cc.10.15.16347.
56. Shiloh Y. ATM and related protein kinases: safeguarding genome integrity. Nat Rev Cancer. 2003;3:155-68.

57. Gubanova E, Brown B, Ivanov SV, Helleday T, Mills GB, Yarbrough WG, et al. Downregulation of SMG-1 in HPV-positive head and neck squamous cell carcinoma due to promoter hypermethylation correlates with improved survival. Clin Cancer res off J am Assoc Cancer Res. 2012;18:1257-67.

58. Sewell A, Brown B, Biktasova A, Mills GB, Lu Y, Tyson DR, et al. Reversephase protein array profiling of oropharyngeal cancer and significance of PIK3CA mutations in HPV-associated head and neck cancer. Clin Cancer Res Off J Am Assoc Cancer Res. 2014;20:2300-11.

59. Dok R, Kalev P, Van Limbergen EJ, Asbagh LA, Vázquez I, Hauben E, et al. p16INK4a impairs homologous recombination-mediated DNA repair in human papillomavirus-positive head and neck tumors. Cancer Res. 2014;74:1739-51.

60. Weaver AN, Cooper TS, Rodriguez M, Trummell HQ, Bonner JA, Rosenthal EL, et al. DNA double strand break repair defect and sensitivity to poly ADPribose polymerase (PARP) inhibition in human papillomavirus 16-positive head and neck squamous cell carcinoma. Oncotarget. 2015;6:26995-7007.

61. Slebos RJC, Jehmlich N, Brown B, Yin Z, Chung CH, Yarbrough WG, et al. Proteomic analysis of oropharyngeal carcinomas reveals novel HPVassociated biological pathways. Int J Cancer J Int Cancer. 2013;132:568-79. https://doi.org/10.1002/ijc.27699.

62. Gary C, Hajek M, Biktasova A, Bellinger G, Yarbrough WG, Issaeva N. Selective antitumor activity of roscovitine in head and neck cancer. Oncotarget. 2016;7:38598-611.

63. Zhang $Y$, Koneva LA, Virani S, Arthur AE, Virani A, Hall PB, et al. Subtypes of HPV-positive head and neck cancers are associated with HPV characteristics, copy number alterations, PIK3CA mutation, and pathway signatures. Clin Cancer Res Off J Am Assoc Cancer Res. 2016;22:4735-45.

64. Muñoz N, Castellsagué X, de González AB, Gissmann L. Chapter 1: HPV in the etiology of human cancer. Vaccine. 2006;24:S1-10. https://doi.org/10. 1016/j.vaccine.2006.05.115.

65. Koneva LA, Zhang Y, Virani S, Hall PB, McHugh JB, Chepeha DB, et al. HPV integration in HNSCC correlates with survival outcomes, immune response signatures, and candidate drivers. Mol Cancer Res MCR. 2018;16:90-102.

66. Berman Tara A, Schiller John T. Human papillomavirus in cervical cancer and oropharyngeal cancer: one cause. two diseases Cancer. 2017;123:2219-29. https://doi.org/10.1002/cncr.30588.

67. Stanley M. Pathology and epidemiology of HPV infection in females. Gynecol Oncol. 2010;117(2 Suppl):S5-10.

68. Nakahara T, Kiyono T. Interplay between NF-kB/interferon signaling and the genome replication of HPV. Future Virol. 2016;11:141-55. https://doi.org/10. 2217/fvl.16.2.

69. Hong S, Laimins LA. Manipulation of the innate immune response by human papillomaviruses., manipulation of the innate immune response by human papillomaviruses. Virus res Virus Res 2017;231, 231:34, 34-240. doi: https://doi.org/10.1016/j.virusres.2016.11.004, https://doi.org/10.1016/j. virusres.2016.11.004

70. Thomas M, Narayan N, Pim D, Tomaić V, Massimi P, Nagasaka K, et al. Human papillomaviruses, cervical cancer and cell polarity. Oncogene. 2008;27:7018-30.

71. Maglennon GA, Mclntosh P, Doorbar J. Persistence of viral DNA in the epithelial basal layer suggests a model for papillomavirus latency following immune regression. Virology. 2011;414:153-63.

72. Stanley MA, Pett MR, Coleman N. HPV: from infection to cancer. Biochem Soc Trans. 2007;35:1456-60. https://doi.org/10.1042/BST0351456.

73. Moscicki A-B, Schiffman M, Kjaer S, Villa LL. Chapter 5: updating the natural history of HPV and anogenital cancer. Vaccine. 2006;24(Suppl 3):S3/42-51.

74. Lesseur C, Diergaarde B, Olshan AF, Wünsch-Filho V, Ness AR, Liu G, et al. Genome-wide association analyses identify new susceptibility loci for oral cavity and pharyngeal cancer. Nat Genet. 2016;48:1544-50.

75. Cullen AP, Reid R, Campion M, Lörincz AT. Analysis of the physical state of different human papillomavirus DNAs in intraepithelial and invasive cervical neoplasm. J Virol. 1991;65:606-12.

76. Hudelist G, Manavi M, Pischinger KID, Watkins-Riedel T, Singer CF, Kubista E, et al. Physical state and expression of HPV DNA in benign and dysplastic cervical tissue: different levels of viral integration are correlated with lesion grade. Gynecol Oncol. 2004;92:873-80.

77. Woodman CBJ, Collins SI, Young LS. The natural history of cervical HPV infection: unresolved issues. Nat Rev Cancer. 2007;7:11-22.

78. Nulton TJ, Olex AL, Dozmorov M, Morgan IM, Windle B, Nulton TJ, et al. Analysis of the Cancer genome atlas sequencing data reveals novel properties of the human papillomavirus 16 genome in head and neck 
squamous cell carcinoma. Oncotarget. 2017:8:17684-99. https://doi.org/10. 18632/oncotarget.15179.

79. Morgan IM, DiNardo $L$, Windle B. Integration of human papillomavirus genomes in head and neck Cancer: is it time to consider a paradigm shift? Viruses. 2017;9:208. https://doi.org/10.3390/v9080208.

80. Gelwan E, Malm I-J, Khararijan A, Fakhry C, Bishop JA, Westra WH. Nonuniform distribution of high-risk human papillomavirus in squamous cell carcinomas of the oropharynx: rethinking the anatomic boundaries of Oral and oropharyngeal carcinoma from an oncologic HPV perspective. Am J Surg Pathol. 2017;41:1722-8.

81. Perry ME. The specialised structure of crypt epithelium in the human palatine tonsil and its functional significance. J Anat. 1994;185(Pt 1):111-27.

82. Marur S, D'Souza G, Westra WH, Forastiere AA. HPV-associated head and neck Cancer: a virus-related Cancer epidemic - A Review of Epidemiology, Biology, Virus Detection and Issues in Management. Lancet Oncol. 2010;11: 781-9. https://doi.org/10.1016/S1470-2045(10)70017-6.

83. Henderson S, Chakravarthy A, Su X, Boshoff C, Fenton TR. APOBEC-mediated cytosine deamination links PIK3CA helical domain mutations to human papillomavirus-driven tumor development. Cell Rep. 2014;7:1833-41.

84. The Cancer Genome Atlas Research Network. Integrated genomic and molecular characterization of cervical cancer. Nature. 2017;543:378-84. https://doi.org/10.1038/nature21386.

85. Bancroft CC, Chen Z, Yeh J, Sunwoo JB, Yeh NT, Jackson S, et al. Effects of pharmacologic antagonists of epidermal growth factor receptor, PI3K and MEK signal kinases on NF-KB and AP-1 activation and IL-8 and VEGF expression in human head and neck squamous cell carcinoma lines. Int J Cancer. 2002;99:538-48. https://doi.org/10.1002/ijc.10398.

86. Lui WWY, Hedberg ML, Li H, Vangara BS, Pendleton K, Zeng Y, et al. Frequent mutation of the PI3K pathway in head and neck cancer defines predictive biomarkers. Cancer Discov. 2013;3:761-9.

87. Zhang J, Chen T, Yang X, Cheng H, Späth SS, Clavijo PE, et al. Attenuated TRAF3 fosters alternative activation of NF-KB and reduced expression of anti-viral interferon, TP53, and RB to promote HPV-positive head and neck cancers. Cancer Res. 2018;78(16):4613-4626. https://doi.org/10.1158/00085472.CAN-17-0642.

88. Nave H, Gebert A, Pabst R. Morphology and immunology of the human palatine tonsil. Anat Embryol (Berl). 2001;204:367-73.

89. Young LS, Dawson CW. Epstein-Barr virus and nasopharyngeal carcinoma. Chin J Cancer. 2014;33:581-90. https://doi.org/10.5732/cjc.014.10197.

90. Chung GT-Y, Lou WP-K, Chow C, To K-F, Choy K-W, Leung AW-C, et al. Constitutive activation of distinct NF-KB signals in EBV-associated nasopharyngeal carcinoma. J Pathol. 2013;231:311-22.

Ready to submit your research? Choose BMC and benefit from:

- fast, convenient online submission

- thorough peer review by experienced researchers in your field

- rapid publication on acceptance

- support for research data, including large and complex data types

- gold Open Access which fosters wider collaboration and increased citations

- maximum visibility for your research: over $100 \mathrm{M}$ website views per year

At $\mathrm{BMC}$, research is always in progress.

Learn more biomedcentral.com/submissions 